\title{
Measuring the Business Value of IT
}

\author{
Paul P. Tallon, John G. Mooney, and Marvin Duddek
}

\begin{abstract}
Firms have consistently struggled to measure the business value of information technology (IT). In an era where IT is transitioning to a services model, firms are replacing capital expenditure with operating expenditure. The implications for IT business value measurement are significant. In this chapter, we examine the state of knowledge about IT business value with particular emphasis on established metrics for IT business value. We then consider how these metrics might be applied to cloudbased services. The move to a services model further provides an opportunity to consider IT business value in a new light by considering how cloud technologies enhance IT agility, how firms can monetise their data, and how firms now have greater flexibility around IT use than ever before.
\end{abstract}

P. P. Tallon $(\bowtie)$

Loyola University Maryland, Baltimore, MD, USA

e-mail: pptallon@loyola.edu

J. G. Mooney $\bullet$ M. Duddek

Graziadio Business School, Pepperdine University, Malibu, CA, USA

(C) The Author(s) 2020

T. Lynn et al. (eds.), Measuring the Business Value of Cloud Computing, Palgrave Studies in Digital Business \& Enabling Technologies, https://doi.org/10.1007/978-3-030-43198-3_1 
Keywords Return on IT investment $\bullet$ Cloud technologies $\bullet$ Net present value $\bullet$ IT performance

\subsection{INTRODUCTION}

In an era defined by rapid adoption of information technology (IT) services and increasing volumes of data, senior IT executives continue to emphasise the need for measuring and managing the business value of IT investments (Kappelman et al. 2019). Annual surveys of top IT executives by the Society for Information Management (SIM) attest to significant growth in IT spending as a percentage of revenues with IT spending growing from 3.8\% of revenues in 2008 to $5.9 \%$ in 2018 (Kappelman et al. 2019). The composition of IT spending has also shifted over time, reflecting the adoption of cloud-based IT services and the associated shift from viewing IT investment as capital expenditure (CapEx) to operating expenditure (OpEx). While data analytics and cybersecurity are among the largest categories of IT spending, spending on cloud computing (Software-as-a-Service-SaaS, Platform-as-a-Service-PaaS, and Infrastructure-as-a-Service-IaaS) is growing and expected to outpace other areas of expenditure in the coming years (Kappelman et al. 2019). This shift will create opportunities for CIOs to rethink how they allocate IT resources. It also puts pressure on CIOs to think about how they should justify and manage new areas of IT spending. In the past, IT projects were required to undergo a significant and often time-consuming budget approvals process. However, the move to cloud computing means that IT investment is no longer up-front but rather distributed over time based on resource utilisation. The net result is that the determination of IT business value has become less of a preoccupation for CIOs and business executives when IT spending-like a subscription for cloud-based services-is regarded as OpEx rather than CapEx. Yet, the overarching question still remains: how can CIOs assess the business value of IT when IT is provisioned and utilised as a service in the cloud? In this chapter, we explore this question by looking beyond current IT business value measurement to ways of evaluating the unique benefits that flow from cloud-based IT services. Much of the benefits of cloud computing, we propose, are found in the ability of organisations to use cloud computing to scale and adapt IT services and to generate process agility through systems development, deployment, and retirement, thereby providing a greater range of IT support and flexibility to critical business functions. 


\subsection{Financial Approaches to Measuring Business VAlue}

Managers have long been advised to think about IT investments through the lens of capital budgeting: an IT investment calls for an initial capital outlay which is followed in later time periods by a stream of predictable benefits that can be modelled as incremental cash flows. Discountingadjusting for the time value of money-can then be applied to produce a true measure of value. In Table 1.1, we summarise standard metrics that IT executives have long considered necessary to help managers compute and articulate the business value of IT. Yet, as Tallon and Kraemer (2006) note, the often intangible nature of some IT benefits such as enhanced customer satisfaction or improved employee morale present intractable cash flow measurement challenges, making it progressively difficult for CIOs and their business partners to accurately determine IT business value.

Recognising the complexity of expressing various IT impacts in terms of incremental cash flows, researchers have turned to alternative metrics to get closer to the actual impacts themselves. These researchers suggest using process-level perceptual measures of business value rather than firmlevel financial measures. Tallon and Kraemer (2007), for example, conclude that perceptual measures are a valid proxy for non-existent or hard-to-find financial measures of IT business value such as those in Table 1.1. Thus, as we turn to the question of how to compute IT business value in an era of cloud services, we can apply findings from the extant literature to propose that perceptual measures are a reasonable way to consider IT business value and that measuring IT business value at the process-level is preferable to pursuing more aggregated firm-level financial measures.

\subsubsection{OpEx Measures of IT Business Value}

Unlike traditional IT investments that are ordinarily regarded as CapEx, spending on cloud-based services using subscription or usage-based payments are treated as OpEx. As such, payments are directly expensed in the income statement in the time period in which the service is consumed. Unless the user has purchased physical hardware or software which is hosted by the cloud provider, the user does not own any IT assets. Absent an IT asset, nothing appears on the balance sheet. This fundamentally alters the conversation around the use of NPV, ROI, IRR, EVA or payback 
Table 1.1 Standard IT investment evaluation metrics

\begin{tabular}{|c|c|}
\hline & Description of metric \\
\hline Net Present & NPV is one of the foremost financial key performance indicators (KPIs) \\
\hline Value (NPV) & $\begin{array}{l}\text { used to evaluate large, capital-intensive IT projects. NPV relies on } \\
\text { accurate cash flow projections extending over the life of the project, } \\
\text { alongside a discount rate which is used to account for the time value of } \\
\text { money. Project approval depends on obtaining a positive NPV. IT } \\
\text { projects can also be compared with one another using NPV whenever } \\
\text { firms need to ration scarce IT capital. }\end{array}$ \\
\hline $\begin{array}{l}\text { Return on } \\
\text { Investment } \\
(\mathrm{ROI})\end{array}$ & $\begin{array}{l}\text { ROI is an accounting-based ratio that compares total project income to } \\
\text { the level of project investment. ROI does not take account of the time } \\
\text { value of money, meaning that projects with a longer-term return window } \\
\text { would be treated on par with projects that generate equal returns over a } \\
\text { shorter time period. Similar to NPV, the accuracy of ROI calculations } \\
\text { depends on being able to identify the scale of future cash flows arising } \\
\text { from an investment. }\end{array}$ \\
\hline $\begin{array}{l}\text { Payback } \\
\text { period }\end{array}$ & $\begin{array}{l}\text { The payback period is a simplistic method that calculates the time needed } \\
\text { for a project to breakeven (recover its investment costs). In a risk averse } \\
\text { firm, managers may gravitate towards IT projects with a shorter payback } \\
\text { period. In practice, payback should not be used in isolation but rather } \\
\text { alongside other metrics that take account of project risk and that consider } \\
\text { the flow of benefits beyond the end of the payback period. }\end{array}$ \\
\hline $\begin{array}{l}\text { Internal Rate } \\
\text { of Return } \\
\text { (IRR) }\end{array}$ & $\begin{array}{l}\text { Given all future cash flows and an upfront investment for an IT project, } \\
\text { IRR is the discount rate that would return a value of zero for NPV. IRR } \\
\text { can be considered the true rate of return in that it takes account of the } \\
\text { time value of money and the flow of value over time. IRR can be } \\
\text { benchmarked against desired or minimum rates of return, including the } \\
\text { weighted cost of capital. }\end{array}$ \\
\hline Economic & EVA—also called economic profit—is a measure of residual value \\
\hline $\begin{array}{l}\text { Value Added } \\
\text { (EVA) }\end{array}$ & $\begin{array}{l}\text { generated by a project after deducting the cost of invested capital. Since } \\
\text { all capital can be allocated to different ends, EVA argues that projects } \\
\text { should be assessed an investment cost. This allows for a more equitable } \\
\text { comparison if managers are in a position to pick from different IT } \\
\text { projects with unique rates of return. }\end{array}$ \\
\hline $\begin{array}{l}\text { Total Cost of } \\
\text { Ownership } \\
\text { (TCO) }\end{array}$ & $\begin{array}{l}\text { TCO captures a multitude of different cost items in a single metric such } \\
\text { as the cost of hardware, software, and services, allocated per application, } \\
\text { user, department, etc. TCO can also be represented as a cost per period } \\
\text { of time. TCO does not take into account the benefit or value to the } \\
\text { organisation of using the underlying resource and is, as such, a } \\
\text { questionable metric unless accompanied by other metrics such as ROI, } \\
\text { NPV or payback period. }\end{array}$ \\
\hline
\end{tabular}

Source: adapted from Keen and Digrius (2003) 
metrics since there is no initial capital outlay in the way that we normally expect an upfront outlay to apply these traditional measures. Any initial outlay is replaced by a stream of payments over time. Unless these payments are predictable as in the case of a fixed subscription price model, it can be difficult to use discounting (as one would with NPV or IRR) to obtain a clear view of the real cash outflows.

In order to fully appreciate why these metrics are problematic in a cloud setting, it is useful to understand why IT projects have traditionally been characterised by large upfront capital outlays that are then depreciated to zero over multiple periods of time. Before the availability of large scale IT resource sharing, organisations had to acquire and own their IT resources. Once the demand for IT resources was established, that IT resource demand could be met with dedicated assets. The rise of server sprawl was an unfortunate albeit predictable side effect of this process if requests for new applications, for example, led to the creation of dedicated servers (McFarlan and Bartlett 2002). If security, trust and data privacy were concerns, it was often seen as better for firms to use dedicated internal IT resources rather than using shared IT resources, either internally with other departments or employees or externally with third parties. Provisioning of dedicated internal IT resources was further complicated by the need for these resources to satisfy peak demand. Since the level of IT resources could not scale easily or quickly, anticipated spikes in demand for IT resources meant that firms had to raise their initial IT investment to the level necessary to satisfy the projected peak, and then carry that excess capacity (and its associated costs) through periods of reduced demand. The net effect of this approach to resource management was to dilute the level of IT business value since some portion of the IT resources lay idle for significant periods yet these resources had to be purchased, managed and would continue to depreciate in value over time, regardless of actual use.

Cloud-based services with their focus on OpEx rather than CapEx transform this dynamic of provisioning IT resources. When firms are faced with the question of whether to build or buy IT functionality, it is increasingly likely that they will buy standardised IT resources off-the-shelf in ways that they can quickly scale usage of the resource. Effectively, the rise of cloud-based "IT-as-services" means that the supply of IT resources should always equal the actual demand for IT. From the perspective of alignment or fit between IT and business strategy-a perennial concern for CIOs (Kappelman et al. 2019) — the availability of on-demand 
cloud-based services means that firms' IT resources are more likely to be persistently aligned with business needs than if they were to build and manage internal IT resources with their attendant delays in responding to IT demands.

Since classic CapEx-based metrics are unable to capture the full portfolio of benefits from cloud-based solutions, CIOs must search for alternative ways to evaluate IT projects. In so doing, they have an opportunity to look outside the strict boundaries of incremental cash flows. There may be intangible benefits - often ignored in NPV and IRR calculations-which can be as valuable and as desirable as tangible benefits. In order to give a full accounting of IT business value in a cloud-based IT services environment, we must be able to correctly identify such impacts, notwithstanding the difficulty of finding or measuring them (Hares and Royle 1994; Keen and Digrius 2003). Some of these qualitative IT benefits are sought in traditional IT investments also, notably improvements in customer satisfaction, employee morale or product and service quality (Hares and Royle 1994 , p. 206). When identifying IT business value derived from the utilisation of cloud computing, there are some very specific impacts that can be evaluated, notably:

1. Resilience: a risk-based measure that speaks to system reliability and availability.

2. Speed of Deployment: since deployment tends to lag any decision to deploy IT resources, this measure assesses the ability of IT to respond to changes in the demand for IT.

3. Scalability: describes how easily and quickly incremental IT resources can be added to (or removed from) the portfolio of IT resources available to distributed users.

4. Organisational Agility: describes how easily and quickly organisations can respond to changes in their business environment and, more importantly, at what cost.

The above metrics provide a window into a range of non-financial impacts. Unfortunately, it can be difficult to quantify these impacts and so the risk of mismeasurement remains. Indeed, it is also possible that firms could pursue cloud-based solutions not because of immediate financial considerations (cost savings, for example) but rather because they see the cloud as enabling them to do things that would otherwise not be possible. Moving to the adoption of cloud computing also opens up possibilities for 
firms to focus more on effective implementation and use of systems and information - the I in IT-rather than continuing to attribute value to ownership of hardware and software - the T in IT. In the next section, we offer a brief example and some detailed discussion on what this might mean for organisations.

\subsection{Beyond Financials: Quantifying Non-Financial Aspects of IT Business Value}

Although the IT business value literature argues that process-oriented perceptual measures are an acceptable proxy for unavailable or difficult-tofind financial measures, managers need to recognise that perceptions are still subject to individual error and bias. Hence, Tallon (2014) argues that IT decision makers may need to rely more on the views of multiple IT and business executives at different levels within the organisation in what he describes as a distributed sensemaking model. Even if one executive has a less than perfect view of how IT is performing, their biased views can be balanced by insights gleaned from other executives within the organisation. Tallon (2014) notes that a key to enabling business executives to improve their ability to perceive IT business value is having IT executives engage in sensegiving activities. CIOs and the information systems function can, in an educative role, assist their business peers in ways to think about IT business value. They are not telling their business partners what to think about IT but rather how to think about IT. One such exercise involves ways to convert intangible views of IT impacts into more tangible outcomes (Hares and Royle 1994, p. 206). We review two such methods below: Scoring and Value Linking.

\subsubsection{Scoving}

Scoring seeks to assign weights and values to different outcome criteria, making it possible to prospectively analyse and compare IT performance under different scenarios (Keen and Digrius 2003). In Table 1.2, we provide a brief demonstration of what this might look like when comparing a cloud-based IT solution to an on-premise solution, using a hypothetical set of weighted decision criteria. Scores are simply the product of weights multiplied by an estimated grade on a scale from -5 to +5 . Grades represent desirable and undesirable outcomes. In the case of undesirable 
Table 1.2 An illustrative example of how scoring can be used to compare IT solutions

\begin{tabular}{lcrrrr}
\hline \multirow{2}{*}{ Decision criteria } & Weights & \multicolumn{2}{c}{ Cloud-based solution } & \multicolumn{2}{c}{ On-premise solution } \\
\cline { 3 - 6 } & & Grade $(-5$ to 5) & Score & Grade (-5 to 5) & Score \\
\hline Enhanced user experience & 15 & 4 & 60 & 4 & 60 \\
Risk of user acceptance & 10 & -1 & -10 & -1 & -10 \\
Scalability & 20 & 5 & 100 & 2 & 40 \\
Failover scenario & 15 & 5 & 75 & 3 & 45 \\
Level of access to information & 10 & 5 & 50 & 3 & 30 \\
Security infrastructure & 20 & 5 & 100 & 3 & 60 \\
Risk of storing data externally & 10 & -3 & -30 & 5 & 50 \\
Total & 100 & & 345 & & 275 \\
\hline
\end{tabular}

Source: adapted from Keen and Digrius (2003, p. 126)

outcomes such as a rise in risk, incrementally undesirable outcomes can be modelled using negative scores.

Although the scoring method is relatively easy to apply, the main challenge is to cope with each individual's subjectivity. In order to overcome the potential for bias, multiple individuals can be asked what they consider to be suitable weights and scores. However, the group must first agree on the range of intangible impacts; otherwise, some key impacts could be missed. Once the overall structure is agreed, those involved in the process may submit their values and an overall weighted score can be determined. Interrater reliability scores could then be used to ascertain the degree of consistency in the group. Furthermore, it would be beneficial if individuals were allowed to discuss their weights and scores so that opposing viewpoints can be identified and reconciled (Buss 1983).

\subsubsection{Value Linking and Value Acceleration}

Value Linking and Value Acceleration are related concepts that aim to financially evaluate how the initial intangible benefits attributed to IT trickle down to the financial performance of the organisation. Whereas Value Linking focuses on the effects that IT has on factors such as revenue and cost, Value Acceleration aims to identify the range of one-off or unique IT impacts (Parker et al. 1988). In order to examine the secondorder or firm-level effects of IT, it is necessary to identify the range of first-order effects at critical points within the value chain. Different 
technologies will impact processes such as supplier relations or product and service innovation in different ways. So, the secondary effects of IT on revenues, for example, can be tied to a host of first-order benefits that tie incremental revenues to enhanced IT-led supplier relations or to enhanced IT-led product or service innovation. A useful starting point is to trace IT impacts back from five broad categories noted by Sassone and Schwartz (1986): operations savings, performance improvements, increased sales, labour savings, and shorter conversion cycles or to critical business processes within the value chain such as supplier relations, customer relations, product and service enhancement, production and operations, and sales and marketing support (Porter 1985; Tallon 2008; Tallon et al. 2000).

\subsection{Beyond Quantification: Holistic Measurement of IT Business Value}

In the end, the determination of IT business value is part art and part science. The inclusion of subjective measurement can never be fully discounted since the causal paths along which IT generates value for organisations are crisscrossed with any number of factors that can confuse the true relationship between IT and business performance. Recognising this, the move to cloud-based IT services suggests that managers may want to consider more holistic measures than simply trying to link IT to financial performance. One way to develop this holistic view of IT business value is to recognise that cloud-based IT solutions generate digital options that allow organisations to scale or to change direction much faster than in cases where the firm owns and runs its own IT resources inside its owned and operated data centre (Sambamurthy 2000; Sambamurthy et al. 2003). Moving to cloud computing also allows us to recognise that at a time when IT services are becoming more standardised, effective application of those services to better manage data and business processes may emerge as sources of competitive differentiation. Any move to recognise data as a strategic asset that can be placed on the balance sheet has been controversial. Yet the literature is beginning to make the case that data should be monetised but that it also requires novel forms of governance (Buff et al. 2015; Short et al. 2011; Tallon et al. 2014). Lastly, one could consider implementing a Business Value Index (BVI), as illustrated by Intel (Curley 2003). BVI considers IT business value on a twodimensional grid. The first dimension-IT Efficiency-asks how well the 
proposed IT investment utilises Intel's established IT infrastructure. The second dimension-Business Value-considers the impact of the proposed IT investment on Intel's business. Investments can be scored as low $(-1)$, medium $(0)$ or high $(+1)$ on each dimension, meaning that investments can be assigned to any one of nine possible positions inside a $3 \times 3$ grid. Potential investments that score low on one or both dimensions are unlikely to be funded, whereas those rated high on one or both dimensions stand a greater chance of being funded. Potential investments that fall between these two extremes can be postponed to a later period in the hopes that IT efficiency and business value might improve, abandoned entirely or could be funded in whole or in part based on the availability of IT resources and the firm's risk propensity (Fichman et al. 2006; Tallon et al. 2002).

\subsubsection{Digital Options in the Cloud}

The challenge with assessing IT business value using a capital budgeting framework is the need to create a model in which benefits and costs are expressed as positive or negative cash flows which are, in turn, restated according to the time value of money. Risky projects are discounted at a higher rate, making it far less likely they will be funded (Kambil et al. 1993; Tallon et al. 2002). If these same IT investments were examined through the lenses of digital options, however, it is entirely possible that an IT investment with a negative net present value could still have a positive options value and be funded on that basis. Moving IT to the cloud provides firms with a variety of options which are often overlooked when using a capital budgeting framework: the option to easily and quickly scale an investment, the option to delay a time-sensitive investment, the option to fund a small-scale pilot project, the option to cancel an investment without penalty or sunk cost, and the option to build out an IT investment in stages (Fichman et al. 2006). As such, an options valuation framework may be a better way to think about creating and managing cloud-based IT investments.

\subsubsection{Monetisation of Big Data}

The discovery during bankruptcy proceedings in 2015 that gaming data housed by Caesars Entertainment was valued at more than $\$ 1$ billion highlights the potential value of data assets that organisations have yet to 
include in the assets section of their balance sheets (Marr 2015). Not all data assets are equally valuable and yet for a growing number of organisations, data is increasingly seen as a strategic asset. The cost of creating or acquiring data is viewed as an operational expense, meaning that the expense is written off in the year in which it is incurred; hence, no portion of the cost is capitalised as an asset for inclusion on the balance sheet. Despite the fact that data might be worth a multiple of what it costs to create, purchase, store, and manage on an ongoing basis, there is no formal mechanism for recognising data as an asset or for determining how data assets should be valued on a continuous basis (Tallon and Scannell 2007). Moving data to the cloud, potentially affords a way to classify data according to its usefulness. Data classification attempts to place data within a lifecycle curve that extends from the moment of its creation (or acquisition) to the moment of its death (or deletion). If cloud storage is priced according to frequency of access, it is possible to isolate data that is frequently used and likely of higher value to the organisation and data that is less frequently accessed and, therefore, of lower value to the organisation.

Besides the question of how data can be valued, there is also the question of how data can be used to create value. The literature has previously spoken of the effects of IT without separating out the incremental effects of technology (hardware, software, and telecoms) from those of data or information. That may be about to change with IT transitioning to the cloud. Research from MIT's Center for Information Systems Research (CISR) describes how data can be monetised by selling, exchange/bartering, and wrapping. In the case of selling, data can be sold to the highest bidder. In the case of exchange/bartering, data may be exchanged for something of equal value. Retailers, for example, may be willing to share data with third parties who, by aggregating data from multiple retailers, are able to uncover insights that may not be discoverable by any one retailer in isolation. Data wrapping meanwhile describes how some organisations such as Fitbit can add data and data analytics features or capabilities to their products or services (Wixom and Schüritz 2018). The use of cloud computing amplifies an organisation's ability to do this given the need for massive storage and computing capabilities to generate customised user experiences with data. What this means is that cloud technologies have made it possible for organisations to monetise data in ways that might not be otherwise possible were data to be locked in silos deep within company-owned data centres. 


\subsection{Additional Considerations for Business Value of Cloud Computing}

The fact that cloud-based IT resources are now regarded as OpEx rather than CapEx does not mean that the CapEx versus OpEx debate has been resolved once and for all. Companies that have moved to an OpEx or services model need to be careful because of how pricing relates to IT resource utilisation. In the same way that apartment leasing in perpetuity can be far more expensive than home ownership, it is possible that cloud costs could, if left unchecked, total to more than if the IT assets were owned and managed by the enterprise itself. It is not sufficient to justify moving to the cloud at a point in time and to then ignore cloud-based costs from that time forward. Whereas the cost of an owned IT asset is a sunk cost-you cannot recoup your entire investment cost if you decide that an IT project is no longer viable-cloud costs are ongoing. What this means is that IT managers will likely need to repeatedly justify their decision to use the cloud. They have the option to bring IT back in-house if costs rise. If the total cost of owning IT drops to where cloud solutions are no longer economically attractive, the CapEx versus OpEx debate could reignite once more.

This discussion is especially relevant in the context of a move by some companies to create platform technologies. At a time when organisations are increasingly structured by business units with geographic, customer, product or market oversight, corporate-managed IT platforms are seen as a way to support certain processes with shared IT resources. The challenge is that some business units might push back against the idea of using shared IT resources to support an activity that they feel is sufficiently unique to warrant direct support from the business unit itself. As argued by Ross et al. (2006), few organisations have mastered the task of building an IT platform that meets both shared and idiosyncratic needs. Dealing with the tension between business units and their corporate parent can mask the same trade-offs between CapEx and OpEx if there is a decision to allow some units to invest in their own IT (CapEx) while others are supported by shared resources in the cloud (OpEx). Here again, managers must question whether standardised IT resources are unable to meet idiosyncratic IT needs as some business units believe or whether simple IT, in the words of Upton and Staats (2008), can meet all IT needs. If all needs can be met through standardised, cloud-based IT, the argument then follows that IT platforms should be implemented using cloud technologies. 
Of course, any move to control business units' IT choices by supporting their IT needs via a shared, corporate-controlled IT platform fails to account for the inevitability of shadow IT. At a time when users can use the cloud to meet any immediate IT resource needs-circumventing IT policies or governance systems that might otherwise cause delays-the lure of cloud-based shadow IT is understandable. As noted by Intel's former Chief Privacy Officer, Malcolm Harkins, the point is not to lock down the use of shadow IT for reasons of risk management or for cost avoidance but rather to create cloud-friendly policies that recognise the value of the cloud when users are pressed for time or resources (Harkins 2013). As long as shadow IT exists within a governance framework that sees the value of allowing users to self-serve when IT platforms are insufficient or when an IT solution must be identified expeditiously, the value of using scalable cloud technologies can be significantly greater than if IT impacts are measured solely through the eyes of the corporate entity.

\subsection{Beyond Measurement to Managing BenEFITS REALISATION}

It is one thing to measure IT business value with any degree of accuracy but it is another thing to manage IT in a way that maximises the potential for value creation. IT business value does not emerge automatically. Lee Iacocca, President, CEO, and Chairman of Chrysler from 1978 to 1992, famously claimed that he had approved so many IT projects involving employee layoffs that there should be nobody working at Chrysler (Iacocca 1989 , p. 243). IT investments are no different in that the promised benefits of IT will only be realised if IT is effectively managed. This means that failed or failing projects may need to be cancelled or redirected if there is a possibility that the expected benefits will not be realised. However, as Keil (1995) observed, cancelling an apparently failing IT project is easier said than done. IT managers are more likely to drag out failing projects long after they should have been paused, cancelled or reviewed. The lesson in this carries over from our prior discussion about moving from CapEx to OpEx. Despite the attractiveness or convenience of cloud technology, there is no point in continuing a subscription to an IT service that has outlived its usefulness or if there is greater value if the underlying technology is brought back in-house. 
Value realisation also means that there should be some form of accountability for effective use of cloud services, since without effective use it will be impossible to realise IT business value (Devaraj and Kohli 2003). Not all forms of IT use will be value generating, but if IT is not used or is not useful, business value will simply fail to arise. It makes sense, therefore, for organisations to use periodic reviews to ascertain if IT resources and services are living up to their promise. So called post-implementation or after-action reviews help managers to discover what works and what doesn't. The reality, however, is that fewer than $30 \%$ of organisations perform any form of post-implementation review once a CapEx investment is live (Tallon et al. 2000). For cloud technology, it is likely to be considerably lower since cost is treated as OpEx and is almost certain to be below the minimum threshold of what most firms need to trigger or justify a post-implementation review. From a cognitive perspective, this means that it may be harder for managers to focus on whether the business value from cloud technologies is appropriate since they may never have to go through any formal review to illustrate the level and locus of IT business value. To avoid such a situation, managers may need to monitor the level and frequency of cloud use and undertake reviews of user satisfaction. User satisfaction is a proxy for business value only insofar as it helps to detect gaps between what users want from IT and what IT does for them.

Lastly, there is a question of whether use of cloud technology creates a risk of over reliance on third-party providers and whether there may be an erosion of critical IT skills from within the organisation. Just as IT outsourcing led some firms to lose key IT skills (Austin et al. 2005), there is a risk that any move to bring IT applications or critical IT infrastructure back in-house might be impeded by a lack of internal IT skills. Such a move could have a detrimental effect on IT benefits in the long term and could lock firms into using less-than-adequate (and expensive) IT solutions.

\subsection{Conclusion}

The movement of IT applications and resources from owned, on-premise assets to third-party cloud-based services has had a profound impact on organisations' ability to use IT to support their business functions. Beyond the benefits of reach and scale and associated impacts on IT risk mitigation and IT support cost, the ability to treat cloud expenses as OpEx rather than CapEx has changed the way that managers think about IT business 
value. From a time when all large capital IT investments were required to undergo a formal cost-benefit assessment prior to acquisition, it is now possible for organisations to avoid such analysis since IT costs are now largely based on IT utilisation and the expense is often believed to be sufficiently low to negate the value of a required cost-benefit analysis. It would be foolhardy for organisations to adopt this view in perpetuity since early indications are that over an extended timeframe cloud-based IT solutions can be as expensive if not more expensive than their on-premise equivalent. There is, as such, a need to think carefully about IT business value in the context of cloud computing. It is not simply a matter of where IT support originates - from the cloud or from a company-owned data centre; IT business value is not the same either way. Transitioning to the cloud uncovers additional types of value (options around process agility, for example) that might not be immediately apparent in on-premise situations, but such a move also triggers the potential for other costs to arise. As the late Andy Grove noted about measurement at Intel, you cannot manage what you cannot measure (Grove 1999). In that regard, cloud computing is no different from any other organisational resource.

\section{REFERENCES}

Austin, R., W. Ritchie, and G. Garrett. 2005. Volkswagen of America: Managing IT Priorities. Harvard Business School Press. [No. 9-606-003].

Buff, A., B.H. Wixom, and P.P. Tallon. 2015. Foundations for Data Monetization. MIT Sloan CISR Working Paper No. 402.

Buss, M.D.J. 1983. How to Rank Computer Projects. Harvard Business Review 61 (1): 118-125.

Curley, M. 2003. Managing Information Technology for Business Value: Practical Strategies for IT and Business Managers. Hillsboro, OR: Intel Press.

Devaraj, S., and R. Kohli. 2003. Performance Impacts of Information Technology: Is Actual Usage the Missing Link? Management Science 49 (3): 273-289.

Fichman, R.G., M. Keil, and A. Tiwana. 2006. Beyond Valuation: Options Thinking in IT Project Management. California Management Review 47 (2): 74-96.

Grove, A.S. 1999. Only the Paranoid Survive: How to Exploit the Crisis Points That Challenge Every Company. New York, NY: Doubleday.

Hares, J.S., and D. Royle. 1994. Measuring the Value of Information Technology. New York, NY: John Wiley.

Harkins, M. 2013. Managing Risk and Information Security: Protect to Enable. New York, NY: Apress Media, LLC. 
Iacocca, L. 1989. Talking Straight. New York, NY: Bantam Books.

Kambil, A., J. Henderson, and H. Mohsenzadeh. 1993. Strategic Management of Information Technology Investments: An Options Perspective. In: R.D. Banker, R.J. Kauffman, M.A. Mahmood (Eds.), Strategic Information Technology Management. Idea Group Publishing: Harrisburg, PA, pp. 161-178.

Kappelman, L., R. Torres, E. McLean, C. Maurer, V. Johnson, and K. Kim. 2019. The 2018 SIM IT Issues and Trends Study. MIS Quarterly Executive 18 (1): $51-84$.

Keen, J.M., and B. Digrius. 2003. Making Technology Investments Profitable: ROI Road Map to Better Business Cases. Hoboken, NJ: Wiley \& Sons.

Keil, M. 1995. Pulling the Plug: Software Project Management and the Problem of Project Escalation. MIS Quarterly 19 (4): 421-447.

Marr, B. 2015. Big Data at Caesars Entertainment-A One Billion Dollar Asset?. Accessed 20 May 2019. https://www.forbes.com/sites/bernard$\operatorname{marr} / 2015 / 05 / 18 /$ when-big-data-becomes-your-most-valuable-asset / \#53eec7131 eef.

McFarlan, F.W., and N. Bartlett. 2002. Postgirot Bank and Provment AB: Managing the Cost of IT Operations. Harvard Business School. [Case 302-061].

Parker, M.M., R.J. Benson, and H.E. Trainor. 1988. Information Economics: Linking Business Performance to Information Technology. Englewood Cliffs, NJ: Prentice Hall.

Porter, M.E. 1985. Competitive Advantage. New York, NY: Free Press.

Ross, J.W., P. Weill, and D.C. Robertson. 2006. Enterprise Architecture as Strategy. Cambridge, MA: Harvard Business School Press.

Sambamurthy, V. 2000. Business Strategy in Hyper-Competitive Environments: Rethinking the Logic of IT Differentiation. In Framing the Domains of IT Management: Projecting the Future Through the Past, ed. R. Zmud, 245-261. Cincinnati, OH: Pinnaflex.

Sambamurthy, V., A. Bharadwaj, and V. Grover. 2003. Shaping Agility Through Digital Options: Reconceptualizing the Role of Information Technology in Contemporary Firms. MIS Quarterly 27 (2): 237-263.

Sassone, P.G., and A.P. Schwartz. 1986. Office Information Systems Cost Justification. IEEE Aerospace and Electronic Systems Magazine 1 (8): 21-26.

Short, J.E., R.E. Bohn, and C. Baru. 2011. How Much Information 2010? Report on Enterprise Server Information. Global Information Industry Center, UC San Diego.

Tallon, P.P. 2008. A Process-Oriented Perspective on the Alignment of Information Technology and Business Strategy. Journal of Management Information Systems 24 (3): 231-272.

- 2014. Do You See What I See? The Search for Consensus Among Executives' Perceptions of IT Business Value. European Journal of Information Systems 23 (3): 306-325. 
Tallon, P.P., and K.L. Kraemer. 2006. The Development and Application of a Process-Oriented Thermometer of IT Business Value. Communications of the AIS 17 (45): 1-52.

- 2007. Fact or Fiction? A Sensemaking Perspective on the Reality Behind Executives' Perceptions of IT. Journal of Management Information Systems 24 (1): 13-54.

Tallon, P.P., and R. Scannell. 2007. Information Lifecycle Management. Communications of the ACM 50 (11): 65-69.

Tallon, P.P., K.L. Kraemer, and V. Gurbaxani. 2000. Executives' Perceptions of the Business Value of Information Technology: A Process-Oriented Approach. Journal of Management Information Systems 16 (4): 145-173.

Tallon, P.P., R.J. Kauffman, H.C. Lucas, A. Whinston, and K. Zhu. 2002. Using Real Options Analysis for Evaluating Uncertain Investments in Information Technology: Insights from the ICIS 2001 Debate. Communications of the Association for Information Systems 9: 136-167.

Tallon, P.P., R.V. Ramirez, and J.E. Short. 2014. The Information Artifact in IT Governance: Towards a Theory of Information Governance. Journal of Management Information Systems 30 (3): 141-177.

Upton, D.M., and B. Staats. 2008. Radically Simple IT. Harvard Business Review 86 (3): 118-124.

Wixom, B.H., and R. Schüritz. 2018. Making Money from Data Wrapping: Insights from Product Managers (Research Briefing). MIT Center for Information Systems Research.

Open Access This chapter is licensed under the terms of the Creative Commons Attribution 4.0 International License (http://creativecommons.org/licenses/ by $/ 4.0 /$ ), which permits use, sharing, adaptation, distribution and reproduction in any medium or format, as long as you give appropriate credit to the original author(s) and the source, provide a link to the Creative Commons licence and indicate if changes were made.

The images or other third party material in this chapter are included in the chapter's Creative Commons licence, unless indicated otherwise in a credit line to the material. If material is not included in the chapter's Creative Commons licence and your intended use is not permitted by statutory regulation or exceeds the permitted use, you will need to obtain permission directly from the copyright holder.

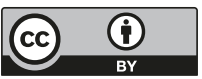

